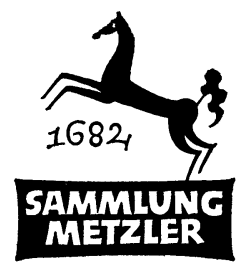

REALIENBÜCHER FÜR GERMANISTEN ABT. D:

LITERATURGESCHICHTE 
ERWIN ROTERMUND

\section{Christian Hofmann von Hofmannswaldau}

MCMLXIII

J. B. METZLERSCHE VERLAGSBUCHHANDLUNG STUTTGART 
Für Edith

ISBN 978-3-476-99720-3

ISBN 978-3-476-99719-7 (eBook)

DOI 10.1007/978-3-476-99719-7

\section{29}

(C) Springer-Verlag GmbH Deutschland 1963 Ursprünglich erschienen bei J. B. Metzlersche Verlagsbuchhandlung und Carl Ernst Poeschel Verlag GmbH in Stuttgart 1963 


\section{VORWORT}

Von der Rehabilitierung der deutschen Barockliteratur im 20. Jahrhundert blieb die Dichtung Hofmannswaldaus, wenn man von wenigen Versuchen absieht, bislang ausgeschlossen. Die Forschung ging an ihr zumeist vorüber oder wertete sie mit den traditionellen Vorwürfen der Frivolität und des „Schwulstes" ab; der literarischen Welt, die dem Werk des Andreas Gryphius existentielles und religiöses Interesse bewies, ist sie weitgehend unbekannt. Erst der zunehmende Sinn für die artifizielle Seite der Dichtung, der, von der Rezeption der ausländischen Moderne nach 1945 gestärkt, sein Korrelat im Stil der neuesten deutschen Lyrik hat, konnte den Blick für verwandte Erscheinungen in der hochbarocken Dichtersprache öffnen. Die sich anbahnende einseitige Auffassung der Werke Hofmannswaldaus als "manieristische“ Kombinationskunst (G.R.Hocke) zeigt aber deutlich die Gefahr eines neuen Mißverstehens.

Solch vorschnellen Einebnungen des Phänomens kann nur eine Analyse begegnen, die auf die isolierende Betrachtung interessanter Einzelzüge verzichtet und über der geistreichen Formkunst Hofmannswaldaus den geformten, vergeistigten Stoff, den gesellschaftlich-historischen wie literaturgeschichtlichen Ort, schließlich die ästhetische Bedeutung dieser Kunst jenseits ihrer zeitlichen Bedingungen nicht vernachlässigt. Sie muß auf den originalen Texten fußen, die wenigen Quellenuntersuchungen der positivistischen und die spärlichen Ansätze der neueren Forschung verwerten, sie muß um die Gründe der jahrhundertealten Ablehnung Hofmannswaldaus wissen. Der vorliegende Band gibt hierzu Material. Daß es auf weiten Strecken in Form kritischer Referate erscheint, bedingte die Forschungslage. Von der ausführlichen Darlegung eines eigenen Deutungsansatzes jedoch nehme ich, der Zielsetzung der >Sammlung Metzlers entsprechend, hier Abstand. 


\section{INHALT}

VoRWORT . . . . . . . . . . . . . V V

I. BIOGRAPHIE . . . . . . . . . . . . . . I I

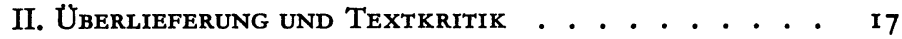

r. Handschriften, Erstdrucke, Neuausgaben . . . . . 17

2. Textkritische Probleme . . . . . . . . . . . . 24

3. Chronologische Fragen . . . . . . . . . . 26

III. Die WeRKE . . . . . . . . . . . . . . . . . . 30

I. Die weltlichen Dichtungen . . . . . . . 30

a) Die Grabschriften . . . . . . . . . . . 30

b) Die erotischen Oden . . . . . . . . . 33

c) Die Sonette . . . . . . . . . . . . . . . . 36

d) Die Heldenbriefe und poetischen Episteln . . . . . 37

e) Die Hochzeitsgedichte . . . . . . . . . . . . 42

f) Die übrigen Gattungen . . . . . . . . . . . . 44

2. Die geistlichen Dichtungen . . . . . . . . 45

a) Die geistlichen Oden . . . . . . . . . . . 45

b) Die Geschichtreden . . . . . . . . . . . . . . 47

c) Die Begräbnisgedichte . . . . . . . . . . . . . 49

d) Die lyrischen Diskurse . . . . . . . . . . 50

3. Die Übersetzungen . . . . . . . . . . . 53

4. Die Poetik (Vorreden) . . . . . . . . . 56

5. Exkurs: Die Erforschung der Metaphorik . . . . . 58

IV. ZUR WIRKUNGSGESCHICHTE . . . . . . . . $6_{3}$

I. Die sogenannte $>Z$ weite Schlesische Schule . . . . . $6_{3}$

2. Fortwirken im 18. und 20. Jahrhundert . . . . . . . $6_{7}$

V. Zur Geschichte der Wertung und ERforschung . . $7 \mathrm{I}$

I. Die Hochwertung im 17. Jahrhundert. . . . . . 7x

2. Die Ablehnung vom 17. Jahrhundert bis zu Gottsched und den Schweizern . . . . . . . . . 73

3. Die Verurteilung in den Literaturgeschichten des 18. und 19. Jahrhunderts . . . . . . . . . . . . 78

4. Die positivistische H.-Forschung . . . . . . . . . 83

5. Die Deutungen des 20. Jahrhunderts . . . . . . .

a) Positive Wertungen . . . . . . . . . . 85

b) Fortleben und Neufundierung der traditionellen Ablehnung .............. 87

Regtster ................... 92 